\title{
Introduction to Statistics in Pharmaceutical Clinical Trials
}

Durham TA, Turner JR. Pharmaceutical Press, London, United Kingdom, 2008. Softcover, 240 pages. ISBN 978-0-85369-714-5. US\$49.99.

Introduction to Statistics in Pharmaceutical Clinical Trials is an introductory statistics textbook intended to teach basic statistical concepts to students in pharmacy, allied health professions, and clinical research. In contrast to the usual format of introductory textbooks on this topic, the authors have presented the basic concepts in the context of clinical trials conducted during devel-

$$
\text { JCPH - Vol. 63, n' } 1 \text { - janvier-février } 2010
$$


opment of pharmaceutical drugs. This textbook explains why and how data are collected in clinical studies, how these data are summarized and analyzed, what the results mean in the context of the clinical research question, and how the results are communicated to regulatory agencies and to the scientific and medical communities.

The book is divided into 13 chapters, beginning with an introduction to the discipline of statistics and its application in confirmatory clinical trials. Chapter 2 outlines the process of developing a new drug. The formulation of research questions and hypotheses is discussed in chapter 3. Chapter 4 provides an overview of study designs and experimental methodologies. Essential statistical topics, including data types, central tendency, variation, probability, and hypothesis-testing, are taught in chapters 5 and 6 . Using the development of a new antihypertensive medication as the common example throughout chapters 7 to 11 , the authors discuss the various statistical methods used to analyze the safety and efficacy data generated by confirmatory clinical trials. Additional statistical considerations, including the estimation of sample size, multicentre trials, population analysis methods, missing data, multiple objectives, equivalence and non-inferiority study designs, and interim and adaptive analyses, are highlighted in chapter 12 . In the final chapter, the authors emphasize the usefulness of statistics in drug development, with the ultimate goal of offering a new biologically active pharmacological agent that will benefit patients. Each chapter includes relevant examples, a list of key references, and exercise questions for students, with solutions at the end of the textbook. Standard statistical tables are included in the appendices. The index is comprehensive and will be helpful for busy practitioners who are using the book as a basic statistics reference.

The authors are highly qualified individuals who have working experience in the statistical aspects of clinical trials and in teaching graduate students in statistics. The book is written in clear language, with detailed explanations of statistical terms. The appropriate use of graphs and tables throughout the text helps the reader to understand important concepts. The rationale for and advantages and limitations of common statistical tests are discussed. Both authors acknowledge their lack of clinical experience, but they overcome this limitation with their excellent communication skills and pragmatic approach to integrating statistical concepts in the context of different types of clinical trials.

The book might have benefited from a few improvements in organization. The important concepts highlighted in chapter 12 , such as sample-size estimation and methods for population analysis, could have been integrated into earlier chapters. These key issues could have been presented in greater detail to allow for more logical flow and better understanding on the part of readers. Information about the application of statistical knowledge in the critical appraisal of published clinical trials would also have been useful.

Overall, the authors achieved their objective of providing students of pharmaceutical sciences and clinical research with a textbook that introduces the methods and application of statistics in clinical trials. This well-written textbook will also serve as a basic statistical resource for allied health professionals in the clinical setting.

Winnie Seto, BScPhm, PharmD, MSc

Pharmacy

Hospital for Sick Children

Toronto, Ontario

\section{Safe and Effective Medication Use in the Emergency Department}

Cohen V. American Society of Health-System Pharmacists, Bethesda, Maryland, 2009. Softcover, 258 pages. ISBN 978-1-58528-233-3. US $\$ 104.00$ (US $\$ 83.00$ for ASHP members).

This first edition of Safe and Effective Medication Use in the Emergency Department is the first text to examine pharmacy practice within the emergency department. It is aimed at pharmacy directors, clinical coordinators, pharmacists, emergency physicians, nurses, and administrators who are seeking to improve medication safety in the emergency department. The book underwent prepublication review by a multidisciplinary team of reviewers, primarily from the author's place of work, the Maimonides Medical Center in Brooklyn, New York.

The stated goals of the book are to "improve deployment of technology . . . or show how to modify technology to achieve regulatory goals and . . . continuity", to "describe pharmacy leadership and management and introduce the PharmER pyramid model as a means to . . . achieve The Joint Commission's Medication Management Standards", and to explain "how to respond to public health emergencies and explain current issues associated with the care of specific patient populations". The book highlights evidence-based practice, where evidence is available, and offers experience or observations where no evidence exists.

The first part of the book is dedicated to reviewing the history, unique challenges, and characteristics of emergency medicine and the history of pharmacy practice within the emergency department. The author also introduces the "PharmER pyramid", a model developed by the Maimonides Medical Center to help avoid medication errors in the emergency department. The second part of the book looks at the "anatomy" of a safe medication-use system. The next portion focuses on quality measures and assuring the quality of high-risk, high-cost medications and response to medical emergencies. The final section looks at the postgraduate specialty residency and undergraduate PharmD rotations offered at Maimonides Medical Center, the role of the pharmacy technician, and the future of clinical pharmacy services in the emergency department.

An obvious strength of this reference is the absence to date of any other texts focusing on issues related to pharmacotherapy in the emergency department; as such, it is a welcome development for emergency practice. It proves to be a good reference for a new practitioner within the area and would be of assistance 